\title{
Investigation of active heated gas filters on metal oxide gas sensors using a microstructured stacked-die setup
}

\author{
Thorsten Graunke ${ }^{3}$, Karina R. Tarantik ${ }^{1}$, Katrin Schmitt ${ }^{1}$, Stefan Raible ${ }^{3}$, Jürgen Wöllenstein ${ }^{1,2}$ \\ ${ }^{1}$ Fraunhofer Institute for Physical Measurement Techniques IPM, Heidenhofstraße 8, 79110 Freiburg \\ ${ }^{2}$ Laboratory for Gas Sensors, IMTEK, University of Freiburg, Germany, \\ 3 ams Sensors Germany GmbH, Gerhard-Kindler-Str. 8, 72770 Reutlingen, Germany \\ thorsten.graunke@ams.com
}

\begin{abstract}
:
This work presents a new approach to improve the selectivity and stability of metal oxide gas sensors by using active heated filter components. The "stacked die" microsystem consists of a micromachined metal oxide gas sensor, a preheater chip and a catalytically active layer on top of the preheater chip. The sensitivity, selectivity and stability of the device have been evaluated using several reactive test gases. Measurements with and without a catalytically active filter layer has been performed. A method for concentration prediction based on the ideal gas law using temperature cycling of the gas has been developed.
\end{abstract}

Key words: gas sensing, active heated catalytic filter, selectivity, microsystem, temperature cycling

\section{Introduction}

A reliable detection especially of toxic or flammable gasses is essential in many applications like fire detection or emission control [1]. Chemical gas sensors based semiconducting metal oxides offer several advantages. Metal oxide sensors, fabricated on silicon substrates provide compatibility with $\mathrm{Si}$ microelectronics and microelectromechanical systems (MEMS). These approaches enable the low cost fabrication of sensors coupled with reduced power consumption via low thermal mass membranes thereby enabling transient temperature operation. However, reliability problems regarding the unambiguity of the
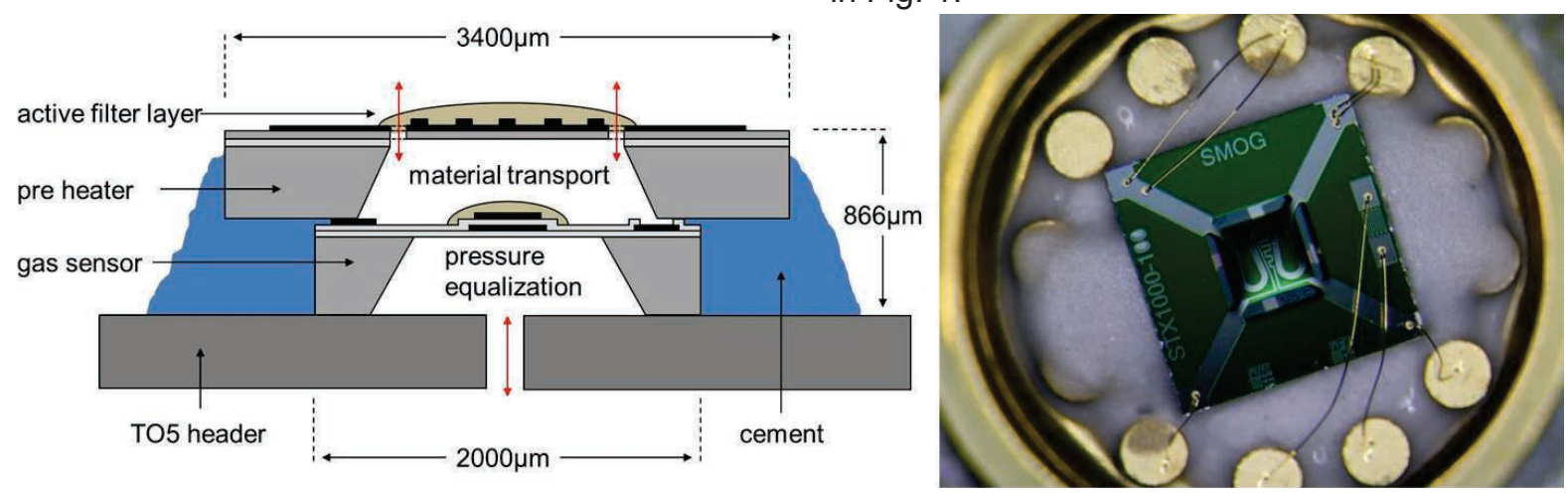

Fig.1. Left: Scheme of the microstructured stacked-die setup with gas sensor and IR emitter as preheater for the active layer. Right: Photograph of a metal oxide sensor with preheater placed on top (without catalytic layer). 
For realizing this setup, on top a TO-5 package with a hole of $0.8 \mathrm{~mm}$ in diameter in the middle a metal oxide gas sensor was placed with gold wire bonded and fixed with cement. Cement was used to avoid sensor fault signal or contamination. The preheater chip is mounted on top of the sensor, bonded and fixed with cement. Due to the fact the preheater (IR emitter) has a so-called "spider design", the hotplate is only fixed at the edges and gas can pass through the small diffusion gap between hotplate and frame. The used two different IR emitters were prepared by Fraunhofer IPM [3] Main differences of the IR emitters, STX-1000-

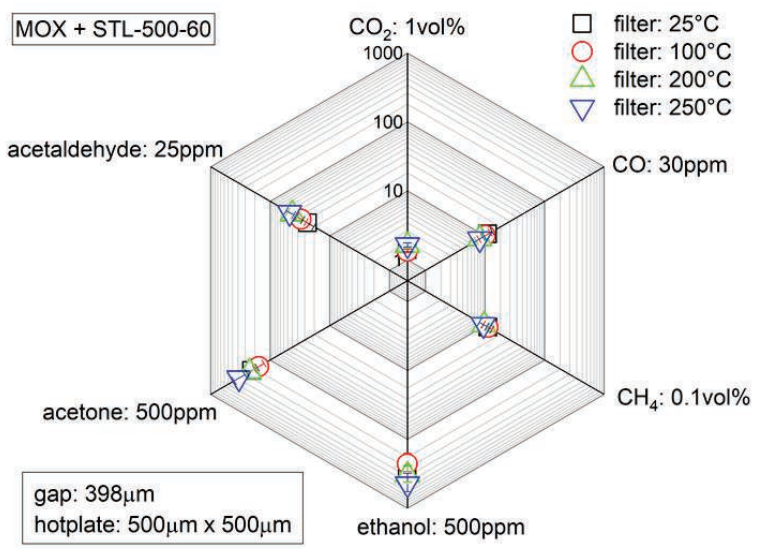

100 and STL-500-60, are in size of the hotplate and the diffusion gap.

The active filter layer was prepared from paste of tin oxide and palladium and calcined on top of the IR emitter. With this microstructured stacked-die setup it was possible to realize very fast heating and cooling rates. For determining the dependence of the amount of substance $n$ on the gas temperature, the IR emitter temperature was raised to reach gas temperatures of $100{ }^{\circ} \mathrm{C}, 200{ }^{\circ} \mathrm{C}$, and $250{ }^{\circ} \mathrm{C}$, respectively, during impinging successively the system with defined concentrations of $\mathrm{CO}_{2}, \mathrm{CO}$, $\mathrm{CH}_{4}$, ethanol, acetone, and acetaldehyde.

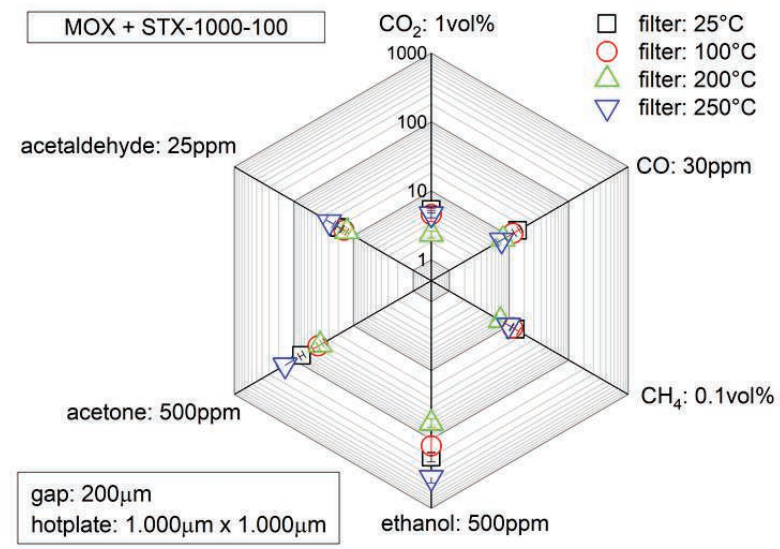

Fig.2. Influence of the gap and hotplate size of the preheater on the decrease of amount of substance at $100{ }^{\circ} \mathrm{C}$, $200{ }^{\circ} \mathrm{C}$ and $250^{\circ} \mathrm{C}$, respectively. Left: Setup with IR emitter STX-1000-100. Right: Setup with chip STL-500-60.

The measurement results show dependence between amount of substance $n$ of a gas in a defined volume and the temperature (see Fig. 2). Therefore, using the microstructured stacked-die setup offers the opportunity to determine the absolute concentration of a single substance or a gas mixture. However, there must be a smaller temperature gradient between the preheater temperature and gas temperature to avoid an additional influence on the amount of substance due to the combustion of gas molecules. Further measurements with this microstructured stacked-die setup has been performed to determine the influence of diffusion, increase of adsorption, catalytic performance of the active layer and humidity on sensor signal for several gases. These MEMSoriented approaches still offers some opportunities for further optimizations like shrinking the diffusion gap by ion etching or vary the distance between metal oxide sensor and active layer.

\section{Conclusion}

The preparation of a stacked-die MEMS setup which consists of a silicon micromachined low power gas sensor a heater platform and a catalytic filter was described. Measurements with different trace gases were performed. The Investigation result in a method for concentration prediction based on the ideal gas law. With the increase of the gas temperature in the cavity volume between preheater and filter the gas concentration decreases. This can be used for the absolute determination of the gas concentration.

\section{References}

[1] R.A. Meyers: Encyclopedia of Analytical Chemistry: John Wiley \& Sons, 2000, Vol. 1-15

[2] S. Herberger et al., Detection of human effluents by a MOS gas sensor in correlation to VOC quantification by GC/MS, Building and Environment, 45 (11), 2430-2439.

[3] J. Hildenbrand et al, Micromachined Mid-Infrared emitter for fast transient temperature operation, IEEE Sensors Journal, 2010, Vol 10. 